\title{
Correction to: World-wide prevalence of Anisakis larvae in fish and its relationship to human allergic anisakiasis: a systematic review
}

\author{
Amene Raouf Rahmati ${ }^{1}$ - Behzad Kiani ${ }^{2}$ - Asma Afshari ${ }^{3}$ - Elham Moghaddas ${ }^{1}$ - Michelle Williams ${ }^{4}$. \\ Shokoofeh Shamsi ${ }^{4}$ (D)
}

Received: 12 February 2021 / Accepted: 18 February 2021 / Published online: 1 March 2021

(C) Springer-Verlag GmbH Germany, part of Springer Nature 2021

\section{Correction to: Parasitology Research} https://doi.org/10.1007/s00436-020-06892-0

\begin{abstract}
The hotspot map in the published document has incorrect hotspot values for some countries, mainly in Asia. The figure is therefore replaced by the corrected figure.
\end{abstract}

Keywords Allergic anisakiasis; hotspot map; Systematic review; Correction

The original published version of this article (Rahmati et al. 2020) contains errors. The correct figure is presented here.

\section{References}

Rahmati AR, Kiani B, Afshari A, Moghaddas E, Williams M, Shamsi S (2020) World-wide prevalence of Anisakis larvae in fish and its relationship to human allergic anisakiasis: a systematic review. Parasitology Research 119:3585-3594 doi:10.1007/s00436-020-06892-0

The online version of the original article can be found at https://doi.org/ 10.1007/s00436-020-06892-0

Handling Editor: Una Ryan

Elham Moghaddas

Moghaddase@mums.ac.ir

$\triangle$ Shokoofeh Shamsi

sshamsi@csu.edu.au

1 Department of Parasitology and Mycology, Faculty of Medicine, Mashhad University of Medical Sciences, Mashhad, Iran

2 Department of Medical Informatics, Faculty of Medicine, Mashhad University of Medical Sciences, Mashhad, Iran

3 Department of Nutrition, Faculty of Medicine, Mashhad University of Medical Sciences, Mashhad, Iran

4 School of Animal and Veterinary Sciences, Graham Centre for Agricultural Innovations, Charles Sturt University, Wagga Wagga, Australia 


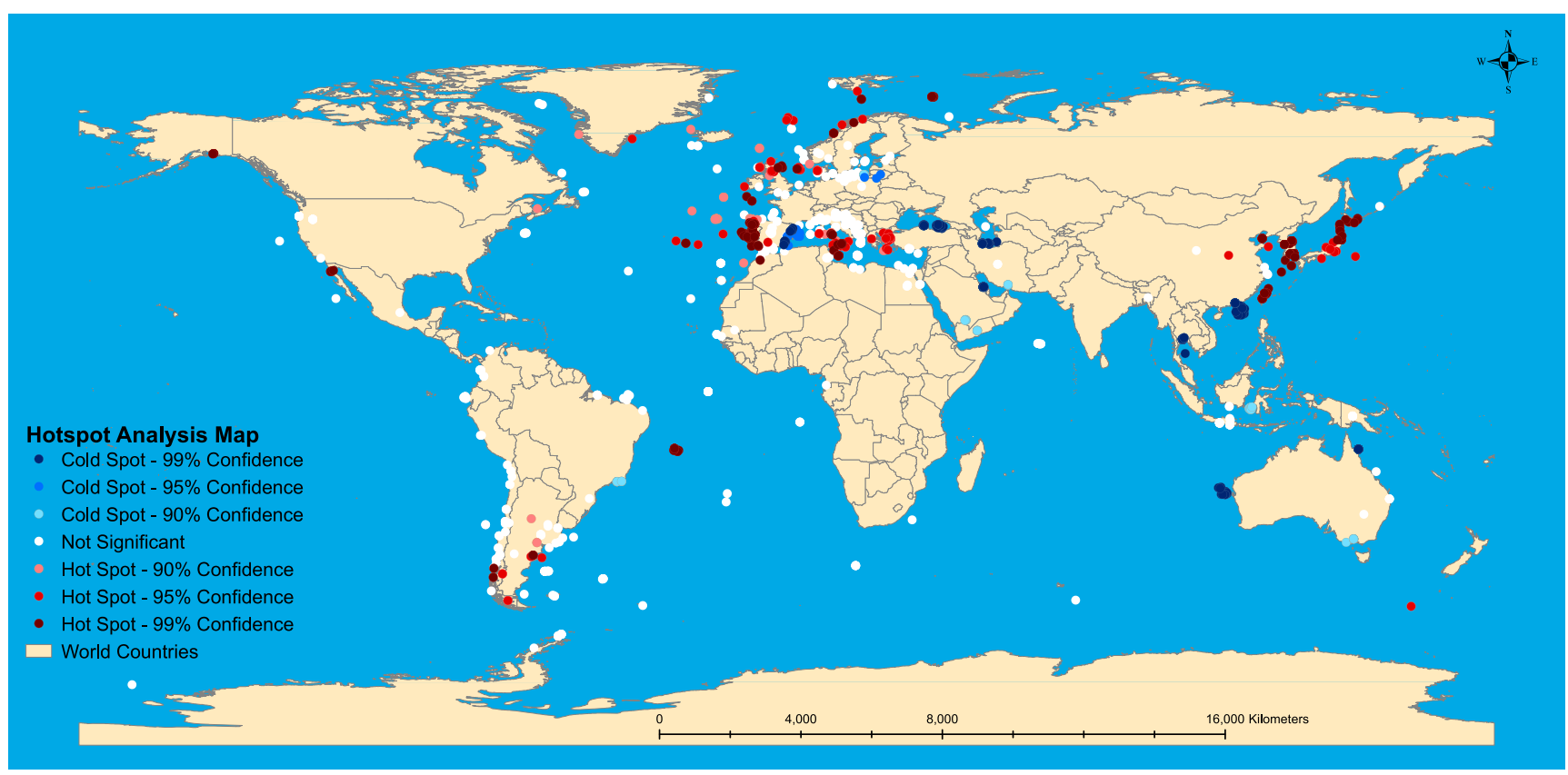

Publisher's note Springer Nature remains neutral with regard to jurisdictional claims in published maps and institutional affiliations. 